vaccines seem to be the commonest source of these accidents (Byers and Moll, 1948), but similar sequelae have been recorded after inoculation of diphtheria, typhoid, and other bacterial antigens as after the disease itself, again notably whooping-cough. These cerebral accidents are commonly regarded as allergic or protein-shock phenomena, the predominating changes being vascular thrombosis. The hypoxia accompanying severe paroxysms is regarded as an important factor in the causation of whooping-cough encephalopathy, which tends to leave permanent residua (Levy and Perry, 1948). The frequent occurrence of convulsions raises the question of an epileptic diathesis or like predisposition, or a trigger mechanism in cerebration which may be released by fever, from whatever cause.

Another theory, which receives less support than formerly, involves the existence of an unidentified encephalitis virus, which in some way is activated by these diseases or by the products of bacterial or viral metabolism. The sporadic appearance of "idiopathic" encephalitis lends some support to this theory (Brain and Hunter, 1929).

\section{Prognosis and Treatment}

The case mortality in the present series was $10 \%$ (the same as in Ford's (1928) series); delirium and coma were sudden in the fatal case and continued to the end five days later. Complicating features were terminal pulmonary oedema and the presence of psittacosis agglutinins in significant titre, but unfortunately a necropsy was refused. The higher fatality rates recorded by some workers were probably due in part to the omission of mild or doubtful cases ; Hamilton and Hanna (1941), in their review of 241 from the literature and 44 of their own, recorded a case mortality of $20 \%$ and a residua rate of $40 \%$.

There were no cases of permanent physical residua in the cases now reported, but two severe cases (Nos. 1 and 9) showed the worst sequelae-behaviour problems and maladjustment. The assessment of the latter is difficult, especially regarding the extent to which the environment perpetuates or improves the condition. The prognosis should always be guarded.

Treatment is largely symptomatic and anticipatory, involving oxygen and chemotherapy, especially when pulmonary or bulbar features are present. When cerebral oedema is suspected, concentrated albumin, plasma, or dextran may be given intravenously-usually three to four times the normal strength. Convalescent serum or gamma globulin may also be tried in the spreading forms of the disease; but little benefit can be expected in the ordinary forms as the initial cerebral assault appears to be maximal in degree and extent, the later changes being biochemical or reactionary and cumulative in their lethal effect. A.C.T.H. was given to two cases (one fatal) on the basis of an allergic aetiology, but seems to have had no effect on the course of the disease or in the prevention of residua, as the case which recovered became severely ataxic and paralysed, with pronounced personality changes.

\section{Summary}

Ten cases of measles meningoencephalomyelitis, three occurring in the pre-eruptive stage, were encountered in a localized area of North-west London between September, 1951, and June, 1953.

The average age of the patients was 5 years, the limits being 20 months and 23 years.

No correlation was observed between the incidence and severity of the disease and the character of the primary disease.

Of the three pre-eruptive cases, one was fatal. This early appearance, and in fact the lack of a fixed timerelationship to the rash, seem to be against the allergic hypothesis of aetiology ; moreover, there was no eosinophilia.
Coma and severe paralyses are unfavourable features, especially if prolonged, but complete recovery may follow.

Predominantly meningitic forms tend to show pronounced fluid changes and encephalitic forms show slight changes, but a high pleocytosis is not incompatible with severe attacks.

Treatment is symptomatic and anticipatory, involving the use of oxygen and chemotherapy for severe forms. Immune sera and concentrated plasma given intravenously may turn the scale in selected cases, especially when cerebral oedema is a prominent feature. The failure of A.C.T.H. to influence the course of the disease (two cases) supports the virus rather than the allergic hypothesis of aetiology ; but the drug was given rather late and in very severe cases.

The case mortality, $10 \%$, equals the lowest recorded in a comparable series.

While physical residua were negligible or absent among the nine recoveries, two patients, both $3 \frac{1}{2}$ years old, showed undoubted mental and behaviour deterioration-in one so pronounced as to require institutional care.

\section{REFERENCES}

Brain, W. R., and Hunter, D. (1929). Lancet, 1, 221 Byers, R. K., and Moll, F. C. (1948). Pediatrics, 1, 437 Comby, M. T. (1935). Les Encéphalites aiguës post-infectieuses de l'enfance. Paris.

Ford. F. R. (1928). Bull. Johns Hopk. Hosp., 43, 140

Hamilton, P. M., and Hanna, R. J. (1941). Amer. J. Dis. Child., 61, 483 Hoyne, A $L$., and Slotkowski, E. L. (1947). Ibid., 73, 554 Levy, S., and Perry. H. A. (1948). Amer. J. ment. Defic., 52, 217 Rolleston, J. D. (1937). The History of the Acute Exanthemata. London. Shaffer, M. F., Rake, G., and Hodes, H. L. (1942). Amer. J. Dis. Child. 64, 815 .

\section{ANTAGONISTIC EFFECT OF A.C.T.H. AND CORTISONE ON THE ANTICOAGULANT ACTIVITY OF ETHYL BISCOUMACETATE}

BY

JYOTI B. CHATTERJEA,* M.D.

Assistant Research Officer, Haematological Unit (Indian Council of Medical Research), School of Tropical Medicine, Calcutta

AND

LUCY SALOMON

Research Assistant, Blood Research Laboratory, New England Center Hospital, Boston

From the Ziskind Laboratories (Haematology Section) of the Joseph $H$. Pratt and New England Center Hospitals. and the Department of Medicine, Tufts College Medical School, Boston, Mass., U.S.A.

In agreement with the observations of Cosgriff et ai. (1950) and Cosgriff (1951), we have noticed a higher incidence of thrombo-embolic complications during administration of A.C.T.H. and cortisone. While treating these complications with the anticoagulant ethyl biscoumacetate (" tromexan") we observed that patients on hormonal therapy would often need a larger dosage to maintain an optimum level of plasma prothrombin activity. On withdrawal of hormonal therapy the requirement of ethyl biscoumacetate decreased considerably.

Two patients were studied-one a case of idiopathic acquired haemolytic anaemia and the other a case of

\footnotetext{
*Working during the tenure of a Rockefeller Fellowship.
} 
acute thrombophlebitis. The dosage schedule of A.C.T.H was 80 to $100 \mathrm{mg}$. daily, administered subcutaneously every six hours. After the full therapeutic effect had been obtained 20 to $25 \mathrm{mg}$. was given daily as maintenance therapy. From 150 to $200 \mathrm{mg}$. of cortisone was given either intramuscularly or orally, and the maintenance dosage was usually one-quarter of the

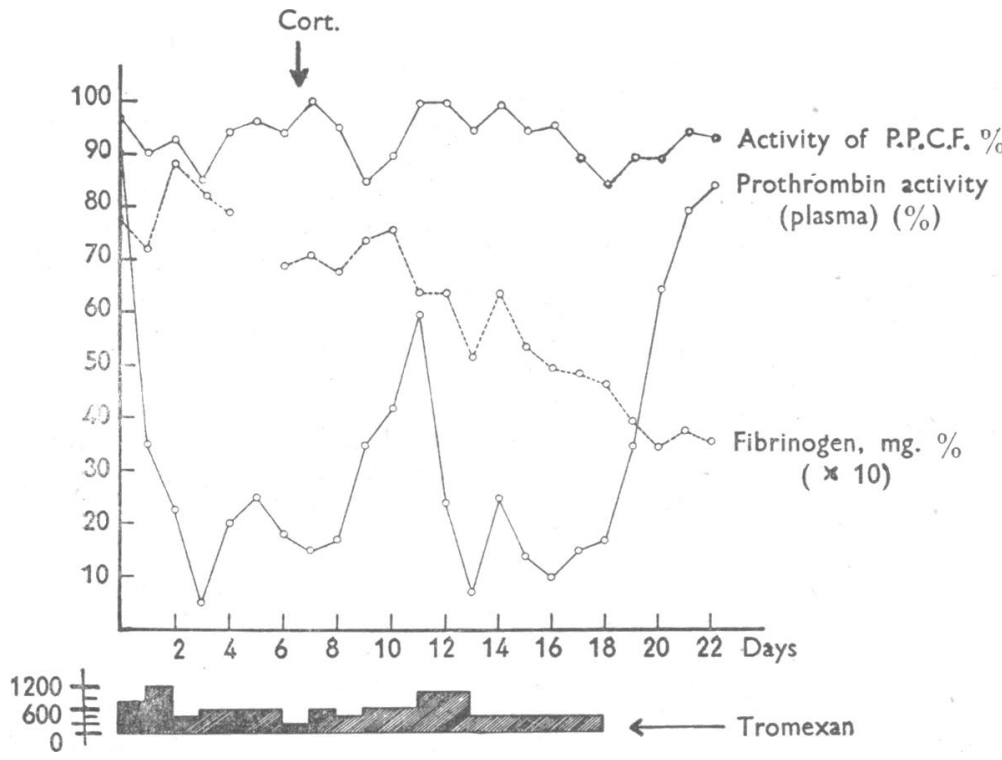

Fig. 1.-Antagonistic effect of cortisone on the anticoagulant activity of ethyl biscoumacetate is shown by the changes in the plasma prothrombin activity in patient suffering from acquired haemolytic anaemia. Activity of plasma prothrombin conversion factor (P.P.C.F., labile factor) shows no significant changes. Plasma fibrinogen level, high before the institution of cortisone therapy, gradually came down to normal level on clinical and haematological improvement.

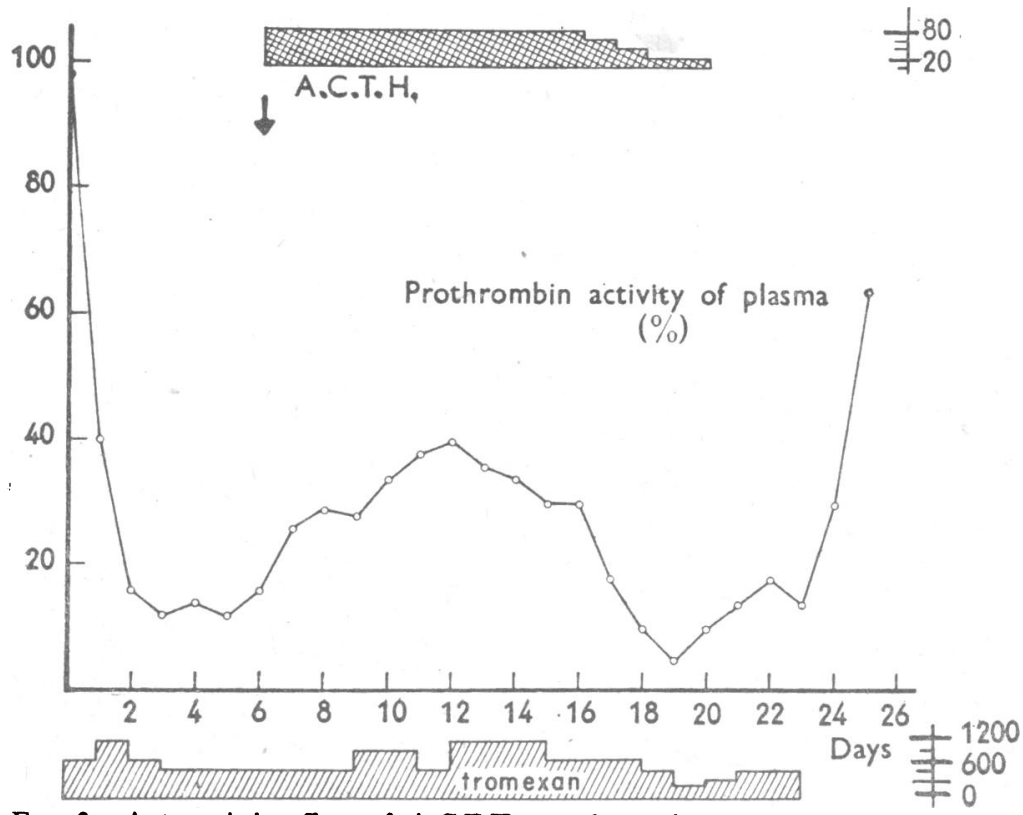

FIG. 2.-Antagonistic effect of A.C.T.H. on the anticoagulant activity of ethyl biscoumacetate is reflected in the behaviour of plasma prothrombin activity in : patient suffering from acute thrombophlebitis.

maximum dosage. Ethyl biscoumacetate was administered in 300 to $1,200 \mathrm{mg}$. daily dosage, the exact requirement being determined in each case by plasma prothrombin activity. Plasma prothrombin activity was determined by a slight modification of the method of Quick (1945); activity of plasma prothrombin conver- sion factor (P.P.C.F., labile factor) by the method of Stefanini (1950); and the plasma fibrinogen level by a slight modification of the method of Quick (1942).

\section{Results}

The first patient developed thrombophlebitis during of cortisone. On the institution of anticoagulant therapy wide fluctuation of plasma prothrombin activity was noted, fluctuation being significant when compared with that seen in control patients not receiving concurrent hormone therapy. The behaviour of plasma prothrombin activity in the two cases studied is shown in Figs. 1 and 2. Fig. 1 shows the relevant data of a female patient with acquired haemolytic anaemia. Her serum contained easily demonstrable autoand iso-red cell antibodies, and the Coombs test was positive. She developed a phlebothrombosis in her left leg while receiving $100 \mathrm{mg}$. cortisone. At this stage, cortisone was discontinued and anticoagulant therapy with ethyl biscoumacetate started. A satisfactory therapeutic level of plasma prothrombin activity was easily obtained. In view of a relapse of the haemolytic process, cortisone therapy was reinstituted on the seventh day of anticoagulant treatment. This was immediately followed by a rise in plasma prothrombin activity, and the dosage of ethyl biscoumacetate had to be increased to obtain an effective therapeutic level. Fig. 2 shows the data in a female patient with acute thrombophlebitis receiving ethyl biscoumacetate. After a satisfactory plasma prothrombin level had been obtained, A.C.T.H. therapy was started deliberately, to study the effect of the hormone on the plasma prothrombin activity. The immediate effect of the A.C.T.H. was to increase the requirement of ethyl biscoumacetate. An effective plasma prothrombin level could be obtained either by increasing the dosage of ethyl biscoumacetate or by decreasing the dosage of A.C.T.H.

\section{Discussion}

Our observations confirm the increase in the incidence of thrombo-embolic complications in the course of A.C.T.H. and cortisone therapy. The mechanism of this phenomenon is not clear. Reports on the effect of A.C.T.H. on the haemostatic process are conflicting. A.C.T.H. may cause temporary thrombocytosis both in the normal and in thrombopenic subjects (Koller and Zollikofer, 1950 ; Dameshek et al., 1950 ; Rosenthal et al., 1951). Cosgriff et al. (1950) observed acceleration of the venous clottingtime and of the heparin-retarded venous clotting-time, suggesting a state of hypercoagulability conducive to thrombo-embolic complications. Smith et al. (1950), on the other hand, found prolonged clotting-time and increase of heparin-like substances, suggesting an anticoagulant action of the hormone. McGraw et al. (1952) gave corticotropin treatment to 12 patients with phlebothrombosis or thrombophlebitis and cortisone to a similar patient. Along with subjective and objective improvement, they observed increased protamine titration values in three patients and significant reduction of prothrombin activity in nine. Fahey (1951), however, failed to detect any significant alteration of the coagulation time with A.C.T.H. in normal human subjects or in patients with hypo- or hyperadrenocorticism. 
Although the mechanism is not clear, it is of considerable importance to be aware of this phenomenon, so that the dosage of ethyl biscoumacetate may be adequate to control thrombo-embolic complications during hormone therapy. Unless absolutely indicated for their known specific effects, A.C.T.H. and/or cortisone should be withheld in the presence of thrombo-embolic complications.

\section{Sunımary}

An increased incidence of thrombo-embolic complications during A.C.T.H. and cortisone therapy was confirmed. During hormone therapy a higher dosage of ethyl biscoumacetate was needed to obtain plasma prothrombin activity at the optimum level.

Our grateful thanks are due to Dr. Mario Stefanini for his valuable help and suggestions.

\section{REFERENCES}

Cosgriff, S. W. (1951). J. Amer. med. Ass., 147, 924.

- Diefenbach, A. F, and Vogt, W, (1950). Amer, J. Med., 9, 752

Dameshek, W., Saunders, R. H., and Zannos, L. (1950). Bull. New Engl. med. Cent., 12, 11.

Fahey, J. L. (1951). Proc. Soc. exp. Biol., N.Y., 77, 491.

Koller, F., and Zollikofer, H. (1950). Experientia, 6, 299.

McGraw, A. B., Margulis, R. R., and Brush, B. E. (1952). Arch. Surg. Chicago, 65, 81 .

Quick, A. J. (1942). The Haemorrhagic Diseases and the Physiology of Haemostasis. Thomas, Springfield, III.

- (1945). Amer. J. clin. Path., 15, 560.

Rosenthal, M. C., Saunders, R. H., Schwartz, L. I., Zannos, L., Santiago E. P., and Dameshek, W. (1951). Blood, 6, 804.

Smith, R. W., Margulis, R. R., Brennan, M. J., and Monto, R. W. (1950) Sclence, 112, 295.

Stefanini, M. (1950). Amer. J. clin. Path., 20, 233.

\section{A CASE OF UVEITIS WITH DEAFNESS THE VOGT-KOYANAGI SYNDROME}

BY

P. K. ROBINSON, M.B., M.R.C.P.

(Assistant Registrar, the National Hospital, Queen Square, London, W.C.1)

Uveitis may be caused by many disease processes, but it was Vogt (1906) who first described a case of nontraumatic uveitis associated with alopecia and greying of the eyelashes and hair. Koyanagi (1929) reviewed the published reports of ten such cases and added six of his own. In his review he summarized a hitherto ill-defined syndrome of uveitis, deafness, alopecia, and loss of pigment in the skin and the hair of the scalp, eyebrows, and eyelashes, which has since been named after these two workers. There is a closely related disease, named after Harada, in which a low-grade uveitis is associated with bilateral detachment of the retina, deafness, alopecia, and pigmentary changes similar to those already described.

The following case of the Vogt-Koyanagi syndrome is described in order to stimulate interest in the early recognition of such cases, so that investigations of the cause may be carried out at an early stage in the disease and perhaps a more specific method of treatment found.

\section{Clinical Picture}

A stoker aged 41 was admitted to the National Hospital under the care of Dr. M. J. McArdle on April 9, 1952. There was no significant family history. Apart from a urethritis of uncertain cause seven years before, he had been in good health.

Three months before admission he noticed swelling of a left inguinal lymph node without apparent cause. Soon after this he developed "a chill" with supraorbital headache and blood-streaked sputum on one occasion. Intermittent headache persisted for three weeks, during which time he noticed the insidious onset of misty vision, beginning in the right eye. Headache cleared spontaneously after a month, but vision slowly deteriorated. A month before admission he began to vomit, had right-sided tinnitus, and noticed difficulty in balancing. Two weeks later he became deaf on the right side, and a week afterwards deaf on the left also, by which time he had continual bilateral tinnitus.

On examination he was afebrile, but looked ill. His vision was R. 6/60, L. $2 / 60$. Mr. Williamson Noble reported a bilateral granulomatous iridocyclitis with keratic precipitates and increase in ocular tension, particularly of the right eye. Haziness of the cornea prevented an adequate view of either fundus. Anosmia was not present. He was completely deaf in the right ear and could only just hear a loud voice with the left. There was no spontaneous nystagmus, although such had been observed just before admission. Caloric responses were absent (Miss Dix). The remaining cranial nerves were normal. There was no weakness, ataxia, sensory loss, or reflex abnormality in limbs or trunk, but the labyrinthine defects caused considerable dysequilibrium. There was no lymphadenopathy, and the chest and abdomen were normal.

Investigations.-C.S.F., April 10, 1952 ; pressure, 180 mm. ; normal dynamics ; 47 cells per c.mm. (93\% lymphocytes, $7 \%$ monocytes) ; protein, $85 \mathrm{mg}$. per $100 \mathrm{ml}$.; Lange curve, 0112210000 ; W.R. (blood and C.S.F.) negative. April 23 : pressure, $180 \mathrm{~mm}$.; 34 lymphocytes per c.mm. ; protein, $75 \mathrm{mg}$. per $100 \mathrm{ml}$.; glucose, $74 \mathrm{mg}$. per $100 \mathrm{ml}$.; chloride, $740 \mathrm{mg}$. per $100 \mathrm{ml}$.; no acid-fast bacilli seen; Löwenstein-Jensen culture and guinea-pig inoculation negative. May 17 : pressure, $145 \mathrm{~mm}$.; 18 cells per c.mm.; protein, $50 \mathrm{mg}$. per $100 \mathrm{ml}$. ; Lange, no change. Full blood count, E.S.R. and serum protein were normal. Mantoux test was positive at 1 in 10,000. Blood agglutination test for brucellosis and dye and complement-fixation tests for toxoplasmosis were negative. $X$-ray examination of the skull, chest, hands, and feet (Dr. Davies and Dr. Thomson) revealed nothing abnormal. Urine : very faint trace of albumin ; no sugar; centrifuged deposit contained a few leucocytes and red blood cells, but no casts.

Atropine drops were instilled into the eyes three times a day. In the next two days vision had deteriorated because of increased opacity of the media and raised ocular tension, but it subsequently began to improve. Although the cause of his meningeal reaction was uncertain he was given a course of penicillin ( 10 million units). Two weeks after admission he had complete and bilateral loss of cochlear and vestibular functions. Vision was R. 6/18 and L. 6/24. Progress was slow, and, since it was thought that the cause of his disease might be viral, a course of aureomycin $(13.5 \mathrm{~g}$.) was given. Mr. Keith Lyle saw the patient a month after admission and observed numerous posterior synechiae, pigment on the anterior lens capsule, turbid anterior chambers, keratic precipitates, and corneal oedema. Hyoscine $\frac{1}{2} \%$ eyedrops were used, afterwards changed to lachesine $1 \%$. Two days later, and about six weeks after admission, he was discharged home. Visual acuity was $6 / 24$ in each eye, but he was deaf in both ears.

One month later his visual acuity was R. 4/60 and L. 6/24. He was admitted to King's College Hospital, under the care of Mr. Keith Lyle, on June 16, 1952. He had a severe bilateral iridocyclitis with raised tension in both eyes, and visual acuity was $6 / 24$ in both eyes. He remained bilaterally deaf. No alopecia, poliosis, or vitiligo was observed on admission, but a few scattered hairs over the temples and some eyelashes turned white later. Diagnostic lumbar and anterior chamber punctures were made and the fluids examined at the Institute of Ophthalmology. No virus was detected. He was treated with cortisone drops and subconjunctival injections and atropine. Visual acuity fluctuated and a paracentesis of the right anterior chamber 